University of Nebraska - Lincoln

DigitalCommons@University of Nebraska - Lincoln

Faculty Publications: Department of Entomology

2010

\title{
Modeling Evolution of Diabrotica virgifera virgifera (Coleoptera: Chrysomelidae) to Transgenic Corn With Two Insecticidal Traits
}

David W. Onstad

University of Illinois, Urbana, onstad@illinois.edu

Lance J. Meinke

University of Nebraska-Lincoln, Imeinke1@unl.edu

Follow this and additional works at: https://digitalcommons.unl.edu/entomologyfacpub

Part of the Entomology Commons

Onstad, David W. and Meinke, Lance J., "Modeling Evolution of Diabrotica virgifera virgifera (Coleoptera: Chrysomelidae) to Transgenic Corn With Two Insecticidal Traits" (2010). Faculty Publications:

Department of Entomology. 260.

https://digitalcommons.unl.edu/entomologyfacpub/260

This Article is brought to you for free and open access by the Entomology, Department of at DigitalCommons@University of Nebraska - Lincoln. It has been accepted for inclusion in Faculty Publications: Department of Entomology by an authorized administrator of DigitalCommons@University of Nebraska - Lincoln. 


\title{
Modeling Evolution of Diabrotica virgifera virgifera (Coleoptera: Chrysomelidae) to Transgenic Corn With Two Insecticidal Traits
}

\author{
DAVID W. ONSTAD ${ }^{1}$ AND LANCE J. MEINKE ${ }^{2}$
}

\begin{abstract}
J. Econ. Entomol. 103(3): 849-860 (2010); DOI: 10.1603/EC09199
ABSTRACT A simulation model of the population dynamics and genetics of western corn rootworm, Diabrotica virgifera virgifera LeConte (Coleoptera: Chrysomelidae), was created to evaluate the use of refuges in the management of resistance to transgenic insecticidal corn, Zea mays L., expressing one or two toxin traits. Hypothetical scenarios and a case study of a corn hybrid pyramided with existing toxins are simulated. In the hypothetical situations, results demonstrated that evolution is generally delayed by pyramids compared with deployment of a single-toxin corn hybrid. However, soil insecticide use in the refuge reduced this delay and quickened the evolution of resistance. Results were sensitive to the degree of male beetle dispersal before mating and to the effectiveness of both toxins in the pyramid. Resistance evolved faster as fecundity increased for survivors of insecticidal corn. Thus, effects on fecundity must be measured to predict which resistance management plans will work well. Evolution of resistance also occurred faster if the survival rate due to exposure to the two toxins was not calculated by multiplication of two independent survival rates (one for each insect gene) but was equivalent to the minimum of the two. Furthermore, when single-trait and pyramided corn hybrids were planted within rootworm-dispersal distance of each other, the toxin traits lost efficacy more quickly than they did in scenarios without single-trait corn. For the case study involving transgenic corn expressing Cry34/35Ab1 and Cry3Bbl, the pyramid delayed evolution longer than a single trait corn hybrid and longer than a sequence of toxins based on at least one resistance-allele frequency remaining below $50 \%$. Results are discussed within the context of a changing transgenic corn marketplace and the landscape dynamics of resistance management.
\end{abstract}

KEY WORDS western corn rootworm, toxin pyramid, resistance management, refuge strategy

The western corn rootworm, Diabrotica virgifera virgifera LeConte (Coleoptera: Chrysomelidae), is a serious pest of corn, Zea mays L., in the United States and Europe (Meinke et al. 2009). The larval stage can cause significant injury to corn roots, leading to reduced plant growth, lodging, increased susceptibility to moisture stress, and reduced grain yield (Gray and Steffey 1998, Urias-Lopez and Meinke 2001). This results in substantial annual investment by producers to reduce economic losses from this pest (Metcalf 1986, Sappington et al. 2006).

The development and commercialization of rootworm-protected transgenic corn hybrids has provided new rootworm management options for producers in the United States. Initial efforts by industry have focused on registration of single events that express Bacillus thuringiensis Berliner proteins with insecticidal activity against the western corn rootworm (Moellenbeck et al. 2001, Vaughn et al. 2005, Walters et al. 2008). However, in recent years, as more rootworm-protected traits have become available, the

\footnotetext{
${ }^{1}$ Corresponding author: Department of Crop Sciences, University of Illinois, Urbana, IL 61801 (e-mail: onstad@illinois.edu).

${ }^{2}$ Department of Entomology, University of Nebraska, Lincoln, NE 68583-0816.
}

product development goal in corn has shifted beyond the single event per hybrid concept to one in which two separate rootworm-protected events are stacked together (pyramid) in the same hybrid. The initial product registration of this type is SmartStax that expresses the pyramided rootworm active proteins Cry3Bb1 and Cry34Ab1 / Cry35Ab1 (United States Environmental Protection Agency 2009). Because the western corn rootworm is very adaptable and has evolved resistance to both synthetic insecticides (Meinke et al. 1998, Miller et al. 2009) and crop rotation (Levine et al. 2002, Gray et al. 2009), scientists, industry, and the U.S. Environmental Protection Agency are concerned about the possible evolution of resistance to transgenic insecticidal corn (Spencer and Levine 2008). To slow the potential evolution of resistance, a structured refuge is currently required in the United States when rootworm-protected transgenic plants are deployed in the field.

Gould et al. (2006) and Roush (1998) used abstract models to study insect resistance management (IRM) for toxin pyramids in plants. Roush (1998) demonstrated that for pyramids to be effective they should use toxins causing very high mortality (high dose). Gould et al. (2006) concluded that fitness costs, i.e., the reduced fitness of resistant phenotypes on non- 
transgenic corn relative to susceptible phenotypes, can be important for resistance evolution and that planting single and multiple-toxin crops near each other can contribute to faster evolution of resistance to both toxins. Roush (1998) drew a similar conclusion about the negative influence of single-toxin crops in his analysis of impurities in insecticidal seeds. Both studies demonstrated the general value of pyramided toxins in IRM.

Several models of the population genetics and dynamics of the western corn rootworm infesting corn hybrids expressing a single toxin have been produced. These studies determined that resistance management is not sensitive to refuge levels between 5 and $20 \%$ (Onstad et al. 2001, Storer 2003). Because both single and multiple-toxin rootworm-protected hybrids will now be planted in the United States, it is important to increase our understanding of the potential for resistance evolution to occur in this system. Therefore, in this analysis, we evaluated IRM for corn hybrids expressing two toxin traits in a pyramid.

\section{Materials and Methods}

This model extends the work of Crowder and Onstad (2005). The time step for calculation is a single generation. The main additions to the model are 1) a second major gene for resistance, 2) possible reductions in fecundity for survivors of insecticidal corn, and 3) reduction in effective refuge because of limited compliance with refuge requirements. The two-gene algorithm was taken from the computer program of Onstad and Buschman (2006).

Population Genetics. We used a simple population genetics model of western corn rootworm in a landscape of continuous corn to explain the evolution of resistance to transgenic corn with two independent insecticidal traits. Two autosomal, di-allelic resistance genes are modeled in the insect population: the first locus has one major gene designated with $\mathrm{X}$ for wild type and $\mathrm{Y}$ for resistance to plant trait 1 , and the second locus has another major gene designated with $\mathrm{S}$ for wild type and $\mathrm{R}$ for resistance to plant trait 2 . We assumed that the two genes are independent of each other, that there are no fitness costs for resistance (i.e., resistant and susceptible individuals are equally fit when reared on conventional corn), and that mutations do not occur after the start of the simulations.

Model Landscape. The region represents a homogeneous region of cropland consisting only of continuous corn planted with transgenic and nontransgenic hybrids. The landscape consists of two types of fields: a field with a block refuge and a block of corn expressing two insecticidal traits, a field with a block refuge and corn expressing only one insecticidal trait. A patch in this model represents either the refuge plants or transgenic insecticidal plants in each field. The proportion of a cornfield that is required to be planted to a nontransgenic hybrid (refuge) is r. Each field can have a different value of $r$.
Compliance With Block and Strip Refuge Requirements. Based on the approach developed by Hurley and Mitchell (2008), we used the following procedure to consider partial compliance with the refuge requirement when the technology is fully adopted by farmers. Let $\mathrm{c}(\mathrm{r})$ be the proportion of farmers (actually cornfields) that comply with the mandated refuge requirement such that $\mathrm{c}(\mathrm{r}) \times(1-\mathrm{r})$ represents the proportion of the pest population inhabiting transgenic insecticidal corn planted by compliant farmers. Assume that the noncompliant farmers do not plant a refuge, then $1-c(r)$ represents the proportion of the population inhabiting transgenic insecticidal corn planted by noncompliant farmers. Adding these two proportions yields the total proportion, $\mathrm{T}$, of the population infesting transgenic insecticidal corn:

$$
\mathrm{T}=\mathrm{c}(\mathrm{r}, \mathrm{f}) \times(1-\mathrm{r})+1-\mathrm{c}(\mathrm{r}, \mathrm{f})
$$

Note that both $r$ and $c$ may be functions of field type f. Hurley and Mitchell (2008) fit the following function to observed compliance rates: $\mathrm{c}(\mathrm{r})=1 /[1+$ $\exp (-2.36+2.31 \mathrm{r})]$. The calculated compliance rate falls from 0.9 to 0.5 as the refuge requirement increases from 0 to 1 . Thus, equation 1 becomes

$$
\mathrm{T}=1-\mathrm{r} /[1+\exp (-2.36+2.31 \mathrm{r})]
$$

In the model, the block patches are adjusted according to the calculated values of $\mathrm{T}$. We either set $\mathrm{c}$ as a constant independent of $\mathrm{r}$ and used equation 1 for each field or let equation 2 calculate $\mathrm{T}$ from $\mathrm{r}$.

\section{Submodel for Adults}

Density of Adults. The densities of males and females emerging in each patch are calculated from the density of older larvae, $\mathrm{L}_{\mathrm{i}, \mathrm{p}}(\mathrm{t})$, surviving competition calculated in equation 10 .

$$
\begin{gathered}
\mathrm{F}_{\mathrm{i}, \mathrm{p}}(\mathrm{t})=\operatorname{RATIO} \times \mathrm{L}_{\mathrm{i}, \mathrm{p}}(\mathrm{t}) \\
\mathrm{M}_{\mathrm{i}, \mathrm{p}}(\mathrm{t})=(1-\mathrm{RATIO}) \times \mathrm{L}_{\mathrm{i}, \mathrm{p}}(\mathrm{t})
\end{gathered}
$$

where $\mathrm{F}$ and $\mathrm{M}$ are the densities of female and males in genotype i emerging in patch $\mathrm{p}$. In generation $t$, RATIO is the proportion of adults that emerge as females.

Male Dispersal. Coats et al. (1987) observed no unmated females flying before the third day after emergence. In a study of dispersal from continuous to first-year cornfields in a region, Godfrey and Turpin (1983) observed $\approx 70-80 \%$ of females in first-year corn by the end of each generation. Because Godfrey and Turpin (1983) observed 3-4 times as many females as males moving into first-year cornfields from continuous corn fields, we assume that $25 \%$ of males disperse outside their natal field. Thus, the proportion of males in a given genotype for each patch, is influenced by PM, the proportion of males that disperse out of the natal cornfield before mating the first or multiple times. To simulate this, we adjusted the number of male beetles that would mate in each patch. 


$$
\begin{aligned}
\mathbf{M}_{\mathrm{m}, \mathrm{p}}(\mathrm{t})= & (1-\mathrm{PM}) \mathbf{M}_{\mathrm{m}, \mathrm{p}}(\mathrm{t})+\sum_{\mathrm{k}=1, \mathrm{k} \text { not } \mathrm{p}}^{4} \mathrm{PM} \\
& \times \mathbf{M}_{\mathrm{m}, \mathrm{k}}(\mathrm{t}) \times\left[\mathrm{P}(\mathrm{p}) / \sum_{\mathrm{n}=1, \mathrm{n} \text { not k }}^{4} \mathrm{P}(\mathrm{n})\right]
\end{aligned}
$$

On the left hand side of equation $4, \mathrm{M}_{\mathrm{m}, \mathrm{p}}(\mathrm{t})$ is the adjusted number of males of genotype m mating in patch $\mathrm{p}$. This is calculated from the number of males of genotype $m$ that emerged and remained in patch $p$ plus the number of males of the same genotype moving into that area from the other areas $\mathrm{k} . \mathrm{P}(\mathrm{p})$ is the proportional area that males are dispersing into and $P(n)$ is the proportion of cornfields that is not the natal area $k$ for group $M_{m, k}(t)$. The adjusted value of $M$ is used to calculate a frequency for each male genotype available for mating in each patch. Note that this function is meant to study proportions leaving the natal patch $<0.5$. In a sensitivity analysis, we examined several other values of PM, including 0 , with equation 4 as well as a model with complete mixing of males in the landscape that omits equation 4 and simply combines all males within a field.

Mating. Unmated females can release pheromone and call for males for at least $3 \mathrm{~d}$ (Hammack 1995). Most females cease calling for males within $24 \mathrm{~h}$ of insemination (Hammack 1995), and insemination causes most females to be either unattractive or unreceptive to males (Hill 1975, Branson et al. 1977). The protandrous adult males emerge earlier than the females and thus are ready to mate as soon as females emerge (Quiring and Timmins 1990). Branson et al. (1977) observed that males could mate an average of eight times during a 42-d period; however, Quiring and Timmins (1990) found that males can mate up to 17 times during their lifetimes.

Under field conditions, essentially all females observed or collected in copula were teneral (Hill 1975, Quiring and Timmins 1990) and from 36\% to $71 \%$ of teneral females $(<1 \mathrm{~d}$ old) were mated when collected (Quiring and Timmins 1990). In the model, all females are mated as teneral adults in the natal patch. During and after male dispersal, random mating occurs in each patch. The frequency of males that are genotype $\mathrm{m}$ in patch $\mathrm{p}$ is $\mathrm{Q}$.

$$
\mathrm{Q}_{\mathrm{m}, \mathrm{p}}(\mathbf{t})=\mathbf{M}_{\mathrm{m}, \mathrm{p}}(\mathrm{t}) /\left[\sum_{\mathrm{i}=1}^{9} \mathbf{M}_{\mathrm{i}, \mathrm{p}}(\mathrm{t})\right]
$$

where $\mathrm{i}$ is genotype.

Storer et al. (2006) observed emergence ending in corn expressing Cry34/35Ab1 toxin at the same time as the emergence from isoline corn. Even if emergence is delayed in transgenic insecticidal corn, the last males emerging from refuge corn can mate with females for $30 \mathrm{~d}$ or more (Quiring and Timmins 1990). In a simulation study, Onstad et al. (2001) concluded that, when sublethal effects of transgenic corn cause susceptible phenotypes to emerge later than normal in a block configuration, resistance can evolve faster

\begin{tabular}{|c|c|}
\hline Major gene(s) & Eggs per female \\
\hline \multicolumn{2}{|c|}{ Single insecticidal trait } \\
\hline $\mathrm{XX}$ & Fecl $\times$ OmaxI \\
\hline $\mathrm{XY}$ & {$[$ Fecl $+(1-\mathrm{Fecl}) \mathrm{hl}] \times$ OmaxI } \\
\hline YY & OmaxI \\
\hline \multicolumn{2}{|c|}{ Two insecticidal traits } \\
\hline XXSS & Fecl $\times$ Fec $2 \times$ OmaxII \\
\hline XYSS & {$[\mathrm{Fecl}+(1-\mathrm{Fecl}) \mathrm{hl}] \times \mathrm{Fec} 2 \times$ OmaxII } \\
\hline YYSS & Fec2 $\times$ OmaxII \\
\hline XXSR & Fec1 $\times[$ Fec $2+(1-$ Fec 2$) \mathrm{h} 2] \times$ OmaxII \\
\hline XYSR & $\begin{array}{l}{[\mathrm{Fecl}+(1-\mathrm{Fec} 1) \mathrm{h} 1] \times[\mathrm{Fec} 2+} \\
\quad(1-\mathrm{Fec} 2) \mathrm{h} 2] \times \text { OmaxII }\end{array}$ \\
\hline YYSR & {$[\mathrm{Fec} 2+(1-\mathrm{Fec} 2) \mathrm{h} 2] \times$ OmaxII } \\
\hline XXRR & Fecl $\times$ OmaxII \\
\hline XYRR & {$[$ Fecl $+(1-$ Fecl $)$ hl $] \times$ OmaxII } \\
\hline YYRR & OmaxII \\
\hline
\end{tabular}

Table 1. Fecundity of females not reaching or remaining on a refuge plant

Parameters hl and h2 indicate the level of dominance for the two major resistance alleles, $\mathrm{Y}$ and $\mathrm{R}$, respectively. OmaxI or OmaxII is the max fecundity for resistant females emerging from a toxic corn plant with one or two toxin traits, respectively. Fecl and Fec 2 are proportions related to the two insecticidal plant traits. Note that either Fecl or Fec2 can be used in the algorithm for a single toxin trait.

when resistance is recessive. When resistance is recessive and only homozygous susceptibles are delayed $6 \mathrm{~d}$, the time to $3 \%$ resistance allele frequency was shortened in situations in which the insecticidal corn was not very efficacious. For example, with $10 \%$ survival of susceptibles, the time to $3 \%$ allele frequency ranged from 51 to $95 \mathrm{yr}$, respectively, for 5 to $30 \%$ refuge. These time periods should be compared with the standard 99 plus years. With recessive resistance and both susceptible homozygotes and heterozygotes delayed $6 \mathrm{~d}$, the resistance allele frequency never changed in the $99 \mathrm{yr}$ of using transgenic corn. When the homozygous susceptibles were delayed by 3-9 d with additive allele expression, resistance evolution did not change (Onstad et al. 2001). Thus, to predict the influence of developmental delays, if they exist, on resistance evolution, we must know whether heterozygotes are delayed as well as whether resistance is recessive.

Oviposition. The fecundity per female emerging in refuge patches is 440 viable eggs (Boetel and Fuller 1997), the standard value used by Onstad in previous western corn rootworm models. The values for all phenotypes emerging in transgenic insecticidal corn patches are shown in Table 1. OmaxI and OmaxII are the values for homozygous resistant beetles; these can be lower than 440 eggs per female. Fecundity depends on the phenotype of the female and the number of insecticidal traits. Fec1 and Fec2 are the proportional multipliers for susceptible beetles that are due to the first and second plant traits. As the dominance values for the resistance alleles ( $\mathrm{h} 1$ and $\mathrm{h} 2$ ) increase, the level of fecundity increases toward OmaxII. Heimpel et al. (2005) explored the influence of reductions in fecundity in an abstract model in which fecundity is independent of host plant trait and insect phenotype.

The eggs are uniformly distributed across the cornfields. The patch label for eggs is the patch in which the eggs will hatch during the next year. 
Egg Density. The number of eggs Ei,p $(t+1)$ of genotype $i$ in patch $p$ for year $t+1$ as a function of the number of female beetles in year $t$ is

$$
\begin{aligned}
\mathrm{E}_{\mathrm{i}, \mathrm{p}}(\mathrm{t}+1)=\mathrm{P}(\mathrm{p}) \times \sum_{\mathrm{g}=1}^{9} \sum_{\mathrm{n}=1}^{4}\left[\mathrm{~b}_{\mathrm{g}, \mathrm{n}} \mathrm{F}_{\mathrm{g}, \mathrm{n}}(\mathrm{t})\right. \\
\left.\quad \times \sum_{\mathrm{m}=1}^{9} \mathrm{w}_{\mathrm{i}, \mathrm{g}, \mathrm{m}} \mathrm{Q}_{\mathrm{m}, \mathrm{n}}(\mathrm{t})\right]
\end{aligned}
$$

where $\mathrm{P}(\mathrm{p})$ is the proportion of each type of seed in the cornfield. $\mathrm{F}$ is the density of females in genotype $\mathrm{g}$ emerging from patch $\mathrm{n}$; $\mathrm{b}$ is the fecundity based on female genotype and natal patch. $Q$ is the frequency of mates that are genotype $m$ in patch $n$. Each weight, w, equals the Mendelian proportion of all offspring that are genotype $\mathrm{i}$ when genotypes $\mathrm{g}$ and $\mathrm{m}$ mate.

\section{Submodel for Larvae}

We modeled the average larva in a genotype in each patch. Immature rootworms may survive four different factors: overwintering, movement between plants, insecticide applications in a block refuge, and corn toxicity.

Immature Survival. Eggs incur an overwintering mortality of $50 \%$ during the egg stage (Godfrey et al. 1995). We evaluated a range of insecticide survival rates for chemicals applied to patches, Si. This survival occurs before density-dependent survival. We assumed that the chemical insecticide does not select for resistance to the chemical insecticide. All genotypes have $100 \%$ survival on refuge plants unless the chemical application harms them; there are no fitness costs.

Crowder and Onstad (2005) assumed that survival to toxin (Stox) is density independent. This is the major assumption made for all models of western corn rootworm. We followed the approach of Crowder and Onstad (2005) and made density-independent toxin mortality incurred by larvae dependent on genotype and the dominance of the resistance allele. We assumed this mortality is applied before competitionbased survival. The two genes have independent, multiplicative effects on resistance. Thus, total survival Stox cannot exceed 1. Table 2 presents the survival rates for each genotype not settling on refuge plants in a patch with one or with two traits. Smin1 and Smin2 are the survival rates due to plant traits 1 and 2. Plant trait one may be expressed alone or combined with plant trait two. In a sensitivity analysis we also explored the consequences of survival equaling the minimum of each term in the products shown for the genotypes in Table 2 (e.g., Min of [Smin1, Smin2] not Sminl $\times$ Smin 2 for XXSS)

Larval Movement. To simulate larval survival in blocks of corn, less knowledge about larval movement is needed to study evolution compared with scenarios with seed mixtures (Onstad 2006). However, to permit reasonable comparison with seed mixture studies in the future, we include the probability of leaving a

\begin{tabular}{|c|c|}
\hline $\begin{array}{l}\text { Major } \\
\text { gene(s) }\end{array}$ & Survival \\
\hline \multicolumn{2}{|c|}{ Single insecticidal trait } \\
\hline $\mathrm{XX}$ & Sminl \\
\hline $\mathrm{XY}$ & $\mathrm{h} 1 \times \operatorname{Smax} 1+(1-\mathrm{h} 1) \times \operatorname{Smin} 1$ \\
\hline YY & Smaxl \\
\hline \multicolumn{2}{|c|}{ Two insecticidal traits } \\
\hline XXSS & $\operatorname{Smin} 1 \times \operatorname{Smin} 2$ \\
\hline XYSS & {$[\mathrm{h} 1 \times \operatorname{Smax} 1+(1-\mathrm{h} 1) \times \operatorname{Smin} 1] \times \operatorname{Smin} 2$} \\
\hline YYSS & $\operatorname{Smax} 1 \times \operatorname{Smin} 2$ \\
\hline XXSR & $\operatorname{Smin} 1 \times[\mathrm{h} 2 \times \operatorname{Smax} 2+(1-\mathrm{h} 2) \times \operatorname{Smin} 2]$ \\
\hline XYSR & $\begin{array}{l}{[\mathrm{h} 1 \times \operatorname{Smax} 1+(1-\mathrm{h} 1) \times \operatorname{Smin} 1] \times[\mathrm{h} 2 \times} \\
\quad \operatorname{Smax} 2+(1-\mathrm{h} 2) \times \operatorname{Smin} 2]\end{array}$ \\
\hline YYSR & $\operatorname{Smax} 1 \times[\mathrm{h} 2 \times \operatorname{Smax} 2+(1-\mathrm{h} 2) \times \operatorname{Smin} 2]$ \\
\hline XXRR & Smin1 $\times$ Smax 2 \\
\hline XYRR & {$[\mathrm{h} 1 \times \operatorname{Smax} 1+(1-\mathrm{h} 1) \times \operatorname{Smin} 1] \times \operatorname{Smax} 2$} \\
\hline YYRR & Smax1 $\times$ Smax 2 \\
\hline
\end{tabular}

Table 2. Probability of survival due to toxicity

Parameters h1 and h2 indicate the level of dominance for the two major resistance alleles $\mathrm{Y}$ and $\mathrm{R}$, respectively.Smin1 and Smin2 are survival for the susceptible homozygotes $\mathrm{XX}$ and SS, respectively. Smaxl and Smax2 are the maximum survival provided by each of the two major resistance alleles $\mathrm{Y}$ and $\mathrm{R}$, respectively. Note that either (Smin1, Smax1) or (Smin2, Smax2) can be used in the algorithm for a single toxin trait.

nontransgenic plant, $\mathrm{Z}$, the probability of leaving a transgenic plant, $\mathrm{V}$, and the proportion surviving dispersal as neonates, SM, in the model. The data of Hibbard et al. (2004) observed $66 \%$ of neonates on the initially infested roots. Therefore, we set $Z=0.5$ and $\mathrm{SM}=0.5($ Onstad 2006). This produces $50 \%$ of original larvae on the initial plant and $25 \%$ on the others $(0.5 /$ $[0.5+0.25]=0.67)$. We set $\mathrm{V}$ to be 0.5 as well.

Equations for Neonates. The following two equations calculate the number of young larvae existing in refuge (rc) and transgenic insecticidal (tc) corn blocks. We assume that no larvae move between refuge and transgenic plants.

$$
\begin{aligned}
\mathrm{N}_{\mathrm{i}, \mathrm{f}, \mathrm{rc}}(\mathrm{t})=0.5 \times\left\{\mathrm{E}_{\mathrm{i}, \mathrm{frc}}(\mathrm{t})\right. & \times(1-\mathrm{Z}) \\
+ & \left.\mathrm{E}_{\mathrm{i}, \mathrm{f}, \mathrm{rc}}(\mathrm{t}) \times \mathrm{Z} \times \mathrm{SM}\right\} \\
\mathrm{N}_{\mathrm{i}, \mathrm{ftc}}(\mathrm{t})=0.5 \times \operatorname{Stox}(\mathrm{f}) & \times\left\{\mathrm{E}_{\mathrm{i}, \mathrm{f}, \mathrm{tc}}(\mathrm{t}) \times(1-\mathrm{V})\right. \\
+ & \left.\mathrm{E}_{\mathrm{i}, \mathrm{ftc}}(\mathrm{t}) \times \mathrm{V} \times \mathrm{SM}\right\}
\end{aligned}
$$

where $f$ is either the field with two insecticidal traits or the field with one trait. The $\mathrm{Y}$ allele or locus 1 provides resistance to the trait in common in the two field types. The $\mathrm{R}$ allele is the gene permitting resistance to the extra trait in field type 2.

Density-Dependent Survival Due to Competition. We assumed that density-dependent mortality occurs after mortality due to overwintering and toxin exposure. The total density per ha, TL, of young larvae in each kind of patch $\mathrm{p}$, is as follows:

$$
\mathrm{TL}_{\mathrm{p}}=\sum_{\mathrm{i}=1}^{9} \mathrm{~N}_{\mathrm{i}, \mathrm{p}}(\mathrm{t}) \times \mathrm{Si}(\mathrm{p}) .
$$

Then, we calculated the number of older larvae surviving density-dependent competition, using a function in the denominator used by Crowder and Onstad (2005) and fully explained in Onstad et al. (2006). 


$$
\begin{aligned}
\mathrm{L}_{\mathrm{i}, \mathrm{p}}(\mathrm{t})=\mathrm{N}_{\mathrm{i}, \mathrm{p}}(\mathrm{t}) /(2.59 \\
\left.+1.29\left\{\mathrm{TL}_{\mathrm{p}} /\left(\mathrm{P}(\mathrm{p}) \times 10^{6}\right)\right\}^{0.88}\right)
\end{aligned}
$$

where the denominator below TL uses $\mathrm{P}(\mathrm{p})$ to convert the larval density to number per ha using the proportional area and uses one million to convert the number to millions per ha. Equation 10 has a maximum larval survival of 0.39 .

\section{Model Analysis}

Verification of the Computer Code. The model is programmed in Visual Basic in Excel 2002 (Microsoft 2002). The program was verified by checking the typical conditions that permit easy identification of errors. We computed the following scenarios to check the logic of the algorithms: no input of insects, no resistance alleles, no wild-type alleles, no refuge, no transgenic insecticidal corn, no selection on fecundity or survival, no mortality except overwintering mortality. We also evaluated the distribution of adults after 1 yr by simulating no mortality and checking distributions across the two fields. We also compared the simulated values for fecundity, toxin survival, and proportion of males to hand-calculated or expected values.

Standard Simulation Conditions. The model has a time-step of one generation $(1 \mathrm{yr})$. The initial number of adults is 50,000 per ha of corn, which is the value used in the model of Onstad et al. (2001). Adults begin at Hardy-Weinberg equilibrium with an initial resistance-allele frequency of 0.0001 for each resistance allele, the value used by Onstad in all previous rootworm models. We assumed no seed impurity and 100\% compliance with refuge requirements in standard simulations. In the standard simulations, resistance expression is additive $(\mathrm{h} 1=\mathrm{h} 2=0.5)$, OmaxI $=$ OmaxII $=440, \mathrm{Fec1}=\mathrm{Fec} 2=0.5, \mathrm{Si}=1, \mathrm{PM}=0.25$, and $\mathrm{V}=\mathrm{Z}=\mathrm{SM}=0.5$.

We evaluated required refuge levels of 5,10 , and $20 \%$. The year in which each allele frequency exceeds $50 \%$ was recorded.

Sensitivity Analysis. In a sensitivity analysis, we studied four factors. First, we evaluated the influence of fecundity of survivors in transgenic corn plants. Second, we studied the influence of initial allele frequency by raising the initial R- and Y-allele frequencies to 0.1 . Third, the sensitivity to premating male dispersal was investigated. Fourth, we studied a different survival algorithm based on minimum survival caused by either of two toxins.

Case Study. We used the observations of Lefko et al. (2008) and Meihls et al. (2008) to investigate a combination of toxin traits that have been approved by the U.S. Environmental Protection Agency (EPA) for pyramided Bacillus thuringiensis (Bt) corn. We used the following model to visually fit a curve to observations of mean population fitness (e.g., larval survival or adult emergence on transgenic corn relative to the same on isoline corn). Given a single locus with two alleles, $\mathrm{r}$ for resistance and $\mathrm{s}$ for susceptibility, the generational change in resistance-allele frequency is as follows:

$$
\begin{aligned}
\mathrm{q}(\mathrm{t}+1)=[\mathrm{q}(\mathrm{t}) \times \mathrm{p}(\mathrm{t}) & \times \operatorname{Wrs}(\mathrm{t})+\mathrm{q}^{2}(\mathrm{t}) \\
& \times \operatorname{Wrr}(\mathrm{t})] / \bar{W}(\mathrm{t})
\end{aligned}
$$

where $W$ ii is the fitness of genotype ii and $t$ is the index for generation. The mean population fitness, $\bar{W}$, is the weighted fitness based on Hardy-Weinberg proportions for each genotype.

$$
\bar{W}=\mathrm{p}^{2} \mathrm{Wss}+2 \mathrm{pq} \mathrm{Wrs}+\mathrm{q}^{2} \mathrm{Wrr}
$$

Equations 11 and 12 are calculated iteratively to evaluate the dynamics of allele frequencies and population fitness changing over a given number of generations. Essentially, four parameters are needed to use the simple model: initial resistance-allele frequency, and either three genotypic fitnesses or two fitnesses for homozygotes and the dominance value, $h$.

Lefko et al. (2008) observed evolution of resistance in two colonies reared on Cry34/35Abl corn over 11 generations on corn seedlings in the laboratory. After one and six generations of selection, the mean population fitness (number of adults divided by number of hatched eggs) was $\approx 0.03$ and 0.20 , respectively, relative to emergence on isoline corn. Lefko et al. (2008) observed 0.004 and 0.013 survival in two colonies during the first generation on Cry34/35Ab1 corn in a laboratory experiment. Storer et al. (2006) observed $0.03,0.04$, and 0.006 relative survival rates in field studies comparing Cry34/35Ab1 corn plots to non-Bt corn plots. With mechanically infested plots, the Storer et al. (2006) field data may not require adjustment for density-dependent mortality (Onstad et al. 2006). Given that a small fraction of the population may be tolerant in all experiments, we assumed that Wss was 0.0125. Based on Lefko et al. (2008), we assumed that Wrr was 0.2 because emergence did not increase over the final five generations. We fit the simple model to the observed population fitnesses and determined that the initial resistance allele is likely between 0.05 and 0.1 with associated dominance values of 0.75 and 0.5 . High values for both parameters were required to match the fast increase in fitness observed during selection.

Meihls et al. (2008) observed evolution of resistance in a colony constantly exposed to Cry3Bbl corn in a greenhouse over six generations. After one and three generations, the mean population fitness was $\approx 0.25$ and 1.0, respectively, relative to the fitness on isoline corn. Thus, we assume that Wrr is 1.0 in the greenhouse.

Based on reciprocal crosses, Meihls et al. (2008) observed intermediate fitnesses for heterozygotes or mixtures of genotypes relative to wild type and those selected for six generations. We used their calculated dominance value $h=0.3$. We fit the simple model to the observations and determined that the initial resistance allele frequency is 0.2 and the Wss is 0.1 . Again, as with the Lefko et al. (2008) data, the initial allele frequency must be high to account for the fast increase in resistance. Note that with initial allele 
frequency of 0.3 , Wss can be as low as 0.01 . (But see below for fit to field data.)

Meihls et al. (2008) also observed mean population fitness in the field. After one generation of selection the adult emergence was 0.013-0.038. After six generations of selection in the greenhouse, larval survival on Cry3Bbl in the field was 0.44 . When we fit the simple model to the field observations, keeping the initial allele frequency the same as determined for the greenhouse $(0.2)$ and setting $\mathrm{Wrr}=0.45$, we found that Wss $=0.001$, and $\mathrm{h}=0.05$ provided the best fit to the observations (i.e., population survival of 0.026 in first generation and 0.44 in third generation). We also concluded that Wrr could not equal 1.0 and initial allele frequency could not be 0.3 under field conditions. Thus, under field conditions, survival is lower and the resistance allele becomes more recessive.

Note that for both Lefko et al. (2008) and Meihls et al. (2008), the wild-type or unselected colony has large numbers of heterozygotes and a few homozygote resistant beetles because of the high initial allele frequency. We assumed that field stresses affect survival on Cry34/35Ab1 corn to the same degree as they do for larvae on Cry3Bb1. Thus, we converted the values for Cry34/35Ab1 corn to Wrr $=0.09=$ Smax1, Wss $=$ $0.001=\mathrm{Smin} 1$, and $\mathrm{h} 1=0.05$ for the simulations of field scenarios with initial allele frequency of 0.1 . In addition, $\operatorname{Smax} 2=0.45, \mathrm{Smin} 2=0.001$, and $\mathrm{h} 2=0.05$ with initial allele frequency equal to 0.2 .

The U.S. EPA (USEPA 2009) has concluded that the mortality caused by Cry34/35Ab1 is $0.9420-0.9918$, that caused by Cry3Bb1 is $0.962-0.9996$, and that caused by corn expressing both traits is $0.9822-0.9997$. Thus, the variability for a given trait is greater than the variability across the highest mortality rates for all three conditions. Furthermore, the combination of traits seems to increase mortality very little if at all. Therefore, we used the minimum survival rate determined from the two terms in the products for each genotype in Table 2. For pyramided corn, the values for the genotypes are (XXSS, 0.001), (XYSS, 0.001), (YYSS, 0.001), (XXSR, 0.001), (XYSR, 0.00545), (YYSR, 0.02295), (XXRR, 0.001), (XYRR, 0.00545), and (YYRR, 0.09). In a sensitivity analysis, we changed Smin1 and Smin2 from 0.001 to either 0.0001 or 0.01 .

L.J.M. et al. (unpublished data) performed a laboratory study to measure fecundity of susceptible survivors from Cry34/35Abl corn and non-Bt corn plots. They collected beetles from field tents in Nebraska to establish cohorts of known age and placed the adults in Plexiglas boxes identified by treatment, replication and emergence date. Adult diet consisted of ears, silks, and leaves obtained from either Cry34/35Ab1 corn or non-Bt corn plots. After random mating for $1 \mathrm{wk}$ in bulk boxes, male and female pairs were randomly chosen from each diet treatment per replication. Each pair was placed in a separate plastic box and provided the appropriate diet per treatment and sterilized moist soil for oviposition. Unselected, wild-type females produced $20-32 \%$ as many eggs after a lifetime (larval through adult) diet of Cry34/35Ab1 corn compared with fecundity of females after a lifetime diet of non-Bt
Table 3. Years to $50 \%$ Y-allele frequency in single-trait block fields

\begin{tabular}{lcccr}
\hline \hline \multirow{2}{*}{ Refuge } & \multicolumn{4}{c}{ Survival of XX } \\
\cline { 2 - 5 } & $0.001^{a}$ & $0.001^{b}$ & 0.05 & 0.2 \\
\hline No insecticide use in refuge & & & & \\
$5 \%$ & 35 & 4 & 5 & 9 \\
$10 \%$ & 38 & 5 & 6 & 9 \\
$20 \%$ & 43 & 6 & 7 & 11 \\
Insecticide use (Si =0.3) & & & & \\
$5 \%$ & 18 & 4 & 5 & 8 \\
$10 \%$ & 34 & 4 & 5 & 9 \\
$20 \%$ & 43 & 5 & 6 & 10 \\
\hline
\end{tabular}

${ }^{a} \mathrm{hl}=0.01$ functional recessive resistance allele

${ }^{b} \mathrm{hl}=0.5$ standard.

corn. Lefko et al. (2008) observed $40 \%$ as much fecundity by resistant survivors in the selected colony reared on Cry34/35Ab1 corn versus the wild-type survivors on non-Bt corn. L.J.M. (unpublished data) also has observed $\approx 50 \%$ reductions in fecundity for survivors of Cry3Bbl. Thus, in the model, OmaxI = $0.4 \times 440=176$ for Cry34/35Abl corn and OmaxI $=$ $0.5 \times 440=220$ for Cry3Bbl corn. OmaxII $=0.4 \times$ $0.5 \times 440=88$ on pyramided corn. Fecl $=0.32 / 0.4=$ 0.8 for Cry $34 / 35 \mathrm{Ab} 1$ corn and Fec $2=1$ (no reduction relative to homozygous resistant beetles but lower than fecundity on non-Bt corn).

\section{Results}

When a single toxin in the corn plants was modeled, resistance never evolved in $<50$ generations (years) when the resistance allele was recessive and the refuge was at least $5 \%$. When resistance was dominant, resistance allele frequency exceeded 0.5 in 5 yr or less with a medium or practical high dose toxin. With dominance and a low dose toxin, resistance evolved in 6-7 yr. With additive resistance, there was very little difference in time to resistance evolution for the practical high and medium doses, but the low dose delayed resistance longer (Table 3 ). If we assume that $\mathrm{h} 1=$ 0.01 when survival is 0.001 , then functional recessive expression of resistance slows evolution significantly.

The addition of a second plant toxin significantly changed the results (Table 4). In general, resistance evolution was delayed. The time to $50 \%$ allele fre-

Table 4. Years to $50 \%$ allele frequency $(Y, R)$ in two-trait block fields with initial allele frequencies 0.0001 and additive resistance for both alleles

\begin{tabular}{|c|c|c|c|c|c|}
\hline \multirow[b]{2}{*}{ Refuge } & \multicolumn{5}{|c|}{ Survival of XX and survival of SS } \\
\hline & $\begin{array}{l}0.001, \\
0.001\end{array}$ & $\begin{array}{c}0.001 \\
0.05\end{array}$ & $\begin{array}{c}0.001 \\
0.2\end{array}$ & $\begin{array}{l}0.05 \\
0.05\end{array}$ & $\begin{array}{c}0.05 \\
0.2\end{array}$ \\
\hline \multicolumn{6}{|c|}{ No insecticide use in refuge } \\
\hline $5 \%$ & 18,18 & 17,17 & 11,15 & 16,16 & 12,14 \\
\hline $10 \%$ & 20,20 & 19,19 & 13,16 & 18,18 & 13,16 \\
\hline $20 \%$ & 23,23 & 21,21 & 15,18 & 20,20 & 15,18 \\
\hline \multicolumn{6}{|c|}{ Insecticide use $(\mathrm{Si}=0.3)$} \\
\hline $5 \%$ & 11,11 & 10,11 & 7,11 & 10,10 & 8,11 \\
\hline $10 \%$ & 17,17 & 16,16 & 11,14 & 15,15 & 11,14 \\
\hline $20 \%$ & 22,22 & 21,21 & 14,18 & 20,20 & 14,17 \\
\hline
\end{tabular}


Table 5. Years to $50 \%$ allele frequency $(Y, \mathbf{R})$ in a landscape consisting of half two-trait block fields with variable refuge level and half single-trait block fields with $20 \%$ refuge (initial allele frequencies 0.0001 and additive resistance for both alleles)

\begin{tabular}{lccccc}
\hline \hline \multirow{5}{*}{ Refuge } & \multicolumn{5}{c}{ Survival of XX and survival of SS } \\
\cline { 2 - 6 } & 0.001, & 0.001, & 0.001, & 0.05, & 0.05 \\
& 0.001 & 0.05 & 0.2 & 0.05 & 0.2 \\
\hline \multicolumn{7}{l}{ No insecticide use in refuge } \\
$5 \%$ & 7,15 & 7,17 & 7,24 & 8,17 & 8,24 \\
$10 \%$ & 8,15 & 7,17 & 7,25 & 8,17 & 8,25 \\
$20 \%$ & 8,16 & 8,19 & 7,28 & 9,19 & 8,28 \\
Insecticide & use $(\mathrm{Si}=0.3)$ & & & & \\
$5 \%$ & 6,14 & 6,16 & 6,23 & 7,16 & 7,23 \\
$10 \%$ & 7,14 & 7,17 & 6,24 & 7,17 & 7,24 \\
$20 \%$ & 7,15 & 7,18 & 7,27 & 8,18 & 8,26 \\
\hline
\end{tabular}

quency was quadrupled for two practical high doses and tripled for two medium doses in comparison with single toxin analyses.

As the percentage refuge declined from 20 to $5 \%$, the use of insecticide in the refuge became more important (Table 4). With insecticide, evolution of resistance occurred $\approx 1$ yr faster with a $20 \%$ refuge but was $7 \mathrm{yr}$ faster with a $5 \%$ refuge. This result is probably driven by the relative difference in susceptible beetles produced by each refuge size. The key point is that soil insecticide use in the refuge can be important when two plant traits control the pest. In other simulations in which we assumed that the practical high dose $($ Smin $=0.001)$ caused the resistance allele to be functionally recessive $(\mathrm{hl}=0.01)$, then evolution of resistance for all cases shown in Table 4 without insecticide use required $>50 \mathrm{yr}$ (Table 4 ). This is similar to previously published results (Onstad et al. 2001, Crowder and Onstad 2005).

Table 5 presents the scenarios in which two kinds of fields were planted. One field had two traits, whereas the other field had plants expressing only the more toxic of the two traits. When $50 \%$ of the corn landscape was planted with a single-trait corn hybrid, the $\mathrm{Y}$ allele for resistance to the more toxic trait expressed in both kinds of fields (practical high dose or medium dose) evolved much more quickly (50-70\% faster). However, the $\mathrm{R}$ allele for resistance to the low-dose trait only expressed in the pyramided field evolved 50\% slower. The single-trait field allowed the initiallyabundant $\mathrm{S}$ allele to last longer when the dose was low. Soil insecticide use in the block refuge had little effect on the results; resistance evolution occurred $\approx 1 \mathrm{yr}$ faster with insecticide use (Table 5). In other simulations, when we assumed that the practical high dose

Table 6. Years to $50 \%$ allele frequency $(Y, R)$ in two-trait block fields with no reduction in fecundity due to plant traits

\begin{tabular}{rccccr}
\hline \hline \multirow{2}{*}{ Refuge } & \multicolumn{5}{c}{ Survival of XX and survival of SS } \\
\cline { 2 - 6 } & $0.001,0.001$ & $0.001,0.05$ & $0.001,0.2$ & $0.05,0.05$ & $0.05,0.2$ \\
\hline $5 \%$ & 13,13 & 13,13 & 8,13 & 11,11 & 8,12 \\
$10 \%$ & 15,15 & 14,14 & 9,14 & 13,13 & 9,13 \\
$20 \%$ & 17,17 & 16,16 & 10,16 & 15,15 & 10,15 \\
\hline
\end{tabular}

Compare results to those in the first three rows of Table 4 .
Table 7. Years to $50 \%$ allele frequency $(Y, R)$ in two-trait block fields with different levels of fecundity independent of plant traits

\begin{tabular}{rcccccr}
\hline \hline & \multicolumn{5}{c}{ Survival of XX and survival of SS } \\
\cline { 2 - 7 } Refuge & \multicolumn{5}{c}{$0.001,0.001$} \\
\cline { 2 - 7 } & \multicolumn{6}{c}{ Eggs per female } \\
\cline { 2 - 7 } & 110 & 220 & 440 & 110 & 220 & 440 \\
\hline $5 \%$ & 20,20 & 18,18 & 13,13 & 11,15 & 10,14 & 8,12 \\
$10 \%$ & $>40$ & 26,26 & 15,15 & 18,22 & 12,16 & 9,13 \\
$20 \%$ & NA & 31,31 & 17,17 & 25,30 & 15,19 & 10,15 \\
\hline
\end{tabular}

NA, not applicable.

was associated with a functionally recessive resistance allele, all cases shown in Table 5 resulted in evolution of resistance requiring $>50 \mathrm{yr}$.

Sensitivity to Fecundity Values. In a sensitivity analysis, plant-trait effects on fecundity were evaluated in two ways. The standard reduction in fecundity by each plant toxin was $50 \%$. First, we eliminated the reduction (and the minimal selection) of fecundity by setting $\mathrm{Fec} 1=\mathrm{Fec} 2=1$. In block refuge fields, resistance evolved $\approx 25 \%$ faster (compared with Table 4) when all phenotypes had the maximum fecundity of 440 eggs per female (Table 6). This result is supported by the results presented in Table 7 , which show that evolution occurs faster as fecundity increases. The differences are greater for larger refuges and for more toxic plant traits.

We also modified the reduction of fecundity due to plant traits. The multiplier Fec was set to 0.25 , 0.5, or 0.75 as the value of Smin changed from $0.001,0.05$, to 0.2 for either gene. The scenario of decreasing fecundity with increasing toxicity resulted in resistance evolving slower with greater reductions in fecundity because of expression of practical high doses of toxin (Table 8). However, resistance evolved slightly faster with lower doses and less negative effect on fecundity (Table 8). Again, these results are supported by Table 7 .

Scenarios With Initial Allele Frequencies of 0.1. To produce a benchmark, we simulated the case with a single toxin. When resistance was recessive, resistance allele frequency exceeded 0.5 in $2-3$ generations (years) for medium and practical high dose toxins and $4-5$ yr for a low-dose toxin. These rates are much faster than those simulated $(>50 \mathrm{yr})$ with an initial allele frequency of 0.0001 . With functionally recessive resistance $(\mathrm{hl}=0.01)$, resistance evolved in $2-3 \mathrm{yr}$ without and 1-2 yr with insecticide use. These latter

Table 8. Years to $50 \%$ allele frequency $(Y, R)$ in two-trait block fields with variable reduction in fecundity due to plant traits

\begin{tabular}{rccccc}
\hline \hline \multirow{2}{*}{ Refuge } & \multicolumn{5}{c}{ Survival of XX and survival of SS } \\
\cline { 2 - 6 } & $0.001,0.001$ & $0.001,0.05$ & $0.001,0.2$ & $0.05,0.05$ & $0.05,0.2$ \\
\hline $5 \%$ & 22,22 & 19,19 & 10,15 & 16,16 & 10,13 \\
$10 \%$ & 24,24 & 20,21 & 12,16 & 18,18 & 11,15 \\
$20 \%$ & 28,28 & 23,23 & 13,18 & 20,20 & 13,17 \\
\hline
\end{tabular}

The fecundity multiplier is $0.25,0.5$, or 0.75 when Smin is either $0.001,0.05$ or 0.2 , respectively. Standard multiplier is 0.5 . 
results are much different from those in Table 3 where functionally-recessive resistance evolved 14-18 times slower. Without soil insecticide, additive resistance evolved in $2 \mathrm{yr}$ for medium to high doses but in $3 \mathrm{yr}$ with a low dose. Results are similar with insecticide use in the block refuge: 1-3 yr with additive resistance. With dominant resistance, resistance evolved in 2-3 yr with a $20 \%$ refuge.

When all cornfields contained hybrids with two toxin traits, resistance evolved in 2-4 yr with or without insecticide use in the block refuges. Results displayed in Table 4 are 4-9 times slower with initial allele frequencies equal to 0.0001 .

In the case with two kinds of fields (one field had two traits while the other field had plants expressing only the more toxic of the two traits), the evolution of resistance was much faster with the higher resistance allele frequency. Without insecticide use in the block refuges, the $\mathrm{Y}$ allele exceeded $50 \%$ in 2-3 yr, whereas the $\mathrm{R}$ allele exceeded $50 \%$ in 5- $6 \mathrm{yr}$ with two high-dose traits and 7-8 yr with medium- and low-dose traits. Thus, resistance occurred $60-70 \%$ faster than the times shown in Table 5. With insecticide use $(\mathrm{Si}=0.3)$ in the block refuges, resistance evolved very fast: $2 \mathrm{yr}$ for the $\mathrm{Y}$ allele and 5-7 $\mathrm{yr}$ for the $\mathrm{R}$ allele. This is $\approx 3-4$ times faster than the case with rare resistance alleles (Table 5).

Sensitivity to Dispersal of Males. We studied the sensitivity of model results to changes in premating dispersal of males for the scenario with two high dose toxins $(\operatorname{Smin} 1=\operatorname{Smin} 2=0.001)$. With a $5 \%$ refuge, the standard result ( $\mathrm{PM}=0.25)$ was 18 yr to $50 \%$ resistance-allele frequencies. With PM ranging from 0, 0.1, 0.2 , to 0.3 , we computed times of $9,21,19$, and $17 \mathrm{yr}$, respectively. With complete mixing of males in the landscape in a different version of the model, evolution of resistance occurred after $13 \mathrm{yr}$ when a $5 \%$ refuge was deployed.

With a $20 \%$ refuge, the standard result $(P M=0.25)$ was 23 yr to $50 \%$ resistance-allele frequencies with two high-dose plant traits. With PM ranging from 0, 0.1, 0.2 , to 0.3 , we computed times of $11,27,24$, and $21 \mathrm{yr}$, respectively. With complete mixing of males in the landscape in a different version of the model, evolution of resistance occurred after $16 \mathrm{yr}$ when a $20 \%$ refuge was deployed.

Nonmultiplicative Survival to Toxins. In this analysis, we set each genotypic survival rate equal to the minimum of the two terms in the products shown in Table 2. This kind of function could be used if we observed 0.001 survival of susceptibles (XXSS) on pyramided corn instead of the $0.001 \times 0.001=$ 0.000001 survival assumed in the algorithm in Table 2. With single-trait fields, the results were the same as those shown in Table 3. For two high-dose toxins and otherwise standard parameters, we calculated 12 and $15 \mathrm{yr}$ to $50 \%$ resistance allele frequencies for 5 and $20 \%$ refuges, respectively. These times are $33 \%$ faster than the standard results in Table 4 . When the refuges are always treated with soil insecticide, the times are reduced further to eight and $14 \mathrm{yr}$ for 5 and $20 \%$ refuges, respectively. Again, these are 25-33\% faster than the
Table 9. Total years to $50 \%$ allele frequency for each of two resistance loci when two, single-toxin corn hybrids are used sequentially for resistance management assuming additive resistance alleles and a block refuge

\begin{tabular}{|c|c|c|c|c|c|}
\hline \multirow[b]{2}{*}{ Refuge } & \multicolumn{5}{|c|}{ Survival of XX and survival of SS } \\
\hline & $\begin{array}{l}0.001 \\
0.001\end{array}$ & $\begin{array}{c}0.001 \\
0.05\end{array}$ & $\begin{array}{c}0.001 \\
0.2\end{array}$ & $\begin{array}{c}0.05 \\
0.05\end{array}$ & $\begin{array}{c}0.05 \\
0.2\end{array}$ \\
\hline & \multicolumn{5}{|c|}{ No soil insecticide use } \\
\hline \multicolumn{6}{|l|}{ Initial allele frequency 0.0001} \\
\hline $5 \%$ & 8 & 9 & 13 & 10 & 14 \\
\hline $20 \%$ & 12 & 13 & 17 & 14 & 18 \\
\hline \multicolumn{6}{|l|}{ Initial allele frequency 0.1} \\
\hline $5 \%$ & 4 & 4 & 5 & 4 & 5 \\
\hline $20 \%$ & 4 & 4 & 5 & 4 & 5 \\
\hline & \multicolumn{5}{|c|}{ Soil insecticide use in refuge } \\
\hline Initial allele frequency 0.0001 & & & & & \\
\hline $5 \%$ & 8 & 9 & 12 & 10 & 13 \\
\hline $20 \%$ & 10 & 11 & 15 & 12 & 16 \\
\hline \multicolumn{6}{|l|}{ Initial allele frequency 0.1} \\
\hline $5 \%$ & 2 & 3 & 4 & 4 & 5 \\
\hline $20 \%$ & 4 & 4 & 5 & 4 & 5 \\
\hline
\end{tabular}

standard values (Table 4). Furthermore, for the scenario with insecticide treated $5 \%$ refuges, we calculated 8 yr to $50 \%$ resistance allele frequencies which only doubled the single, high-dose trait time shown in Table 3. In general, insecticide use in refuges tended to negate the value of pyramids.

Sequential Deployment of Toxin Traits. We assumed that sequential implementation is efficient and that the second gene will evolve resistance at the time equal to the sum of the times to resistance for each gene. Thus, Table 9 presents the total years for the five combinations of toxin traits considered in this study. With the standard initial allele frequency, in only one case $(5 \%$ refuge and pyramid of medium and low dose traits) did a sequence delay resistance longer than the pyramid. If initial allele frequencies are as high as 0.1, then the results indicate that sequential use of toxin traits in transgenic corn will delay resistance at least as well as, and in most cases longer than, pyramids when all fields are the same. This was true for any dose, any refuge level from 5 to $20 \%$, and with or without insecticide use.

Case Study. Table 10 presents the number of years required for the western corn rootworm to evolve resistance to single toxin traits. Given the greater selection pressure and higher initial allele frequency of the gene for resistance to Cry3Bb1, it is not surprising

Table 10. Years to $50 \%$ resistance-allele frequency in singletrait block fields

\begin{tabular}{lrr}
\hline \hline \multirow{2}{*}{ Refuge } & \multicolumn{2}{c}{ Yr for allele for resistance to } \\
\cline { 2 - 3 } & Cry3Bb1 corn & Cry34/35Ab1 corn \\
\hline No insecticide use in refuge & \\
$5 \%$ & 1 & 8 \\
$10 \%$ & 2 & 10 \\
$20 \%$ & 3 & 12 \\
Insecticide use in refuge $(\mathrm{Si}=0.3)$ & \\
$5 \%$ & 1 & 4 \\
$10 \%$ & 1 & 8 \\
$20 \%$ & 2 & 11 \\
\hline
\end{tabular}


that the allele evolved faster than the allele for resistance to Cry34/35Ab1. Insecticide use in the refuge seemed to reduce the durability of Cry34/35Ab1 corn more than Cry3Bb1 (Table 10).

When the two traits were pyramided and no singletrait fields existed, the time to $50 \%$ allele frequency for both resistance genes was generally much longer than the sum of the times for separate toxins. Both resistance-allele frequencies exceeded $50 \%$ after $50 \mathrm{yr}$ when a $5 \%$ block refuge was implemented. With a $20 \%$ block refuge, 62-64 yr passed before allele frequencies exceeded $50 \%$ even if the refuge was always treated with insecticide. The evolution of resistance was twice as fast $(22 \mathrm{yr})$ when the $5 \%$ refuge was always treated with insecticide.

In a sensitivity analysis, we reduced the survival rates for XXSS on both toxins to $0.0001(10 \times$ lower than standard) and found that the time to $50 \%$ resistance-allele frequency changed by a maximum of $1 \mathrm{yr}$. Results were more sensitive to increases in survival. When both survival rates were 0.01 and a $20 \%$ refuge was used, evolution took $7-10 \%$ longer. With a $5 \%$ refuge, evolution of resistance took $6 \%$ (3 yr) longer with untreated refuges and 20\% (5 yr) longer with treated refuge compared with the standards.

In another sensitivity analysis, we modified male dispersal before mating. When PM $=0$ instead of 0.25 , and all males remained in the natal patch to mate, resistance allele frequencies exceeded $50 \%$ after $87 \mathrm{yr}$ with a $20 \%$ refuge in comparison with the $63 \mathrm{yr}$ in the standard model. With PM $=0.1$, a $20 \%$ refuge delayed resistance evolution $>100 \mathrm{yr}$. When we varied PM from 0.2 to 0.3 , the years to resistance changed to 73 and 55, respectively. Thus, a small dispersal rate is good for IRM, but evolution of resistance occurs faster as male dispersal out of the corn blocks increases. When the model permitted complete mixing of males throughout the landscape and a $20 \%$ refuge was used, resistance allele frequencies exceeded $50 \%$ in $31 \mathrm{yr}$, twice as fast as the standard simulation.

Results were similar for scenarios with a $5 \%$ refuge. When $\mathrm{PM}=0$, resistance allele frequencies exceeded $50 \%$ after $60 \mathrm{yr}$ in comparison with the $50 \mathrm{yr}$ in the standard model. With PM $=0.1$, a $5 \%$ refuge delayed resistance evolution $75 \mathrm{yr}$. When we varied PM from 0.2 to 0.3 , the years to resistance changed to 58 and 43 , respectively. When the model permitted complete mixing of males, resistance allele frequencies exceeded $50 \%$ in $25 \mathrm{yr}$, twice as fast as the standard simulation.

Resistance evolved faster when two kinds of cornfields were placed in the landscape; half of the fields were planted with pyramided corn and half were planted with Cry34/35Ab1 corn (Table 11). As expected, the allele conferring resistance to Cry34/ $35 \mathrm{Abl}$ evolved faster in the landscape because it could evolve faster in the single-trait cornfields. When IRM compliance fell to $50 \%$ in the single-trait fields with insecticide use in the refuges, one resistance allele exceeded $50 \%$ after $14 \mathrm{yr}$ and the other after $28 \mathrm{yr}$ (Table 11). The pattern was similar when the singletrait field was always planted with Cry3Bbl corn. Re-
Table 11. Years to $50 \%$ resistance-allele frequencies in a landscape consisting of half two-trait block fields with variable refuge level and half single-trait block fields (Cry34/35Ab1) with $20 \%$ refuge. Standard conditions included a block refuge with variable refuge, no multiplicative effects of toxins, and no random mating $(P M=0.25)$

\begin{tabular}{llc}
\hline \multicolumn{1}{c}{ Scenario } & \multicolumn{2}{c}{$\begin{array}{c}\text { Yr for the allele } \\
\text { resistant to }\end{array}$} \\
\cline { 2 - 3 } & Cry3Bb1 $\quad$ Cry34/35Ab1 \\
\hline No insecticide use in refuge & 39 & 25 \\
$5 \%$ refuge in 2-trait field & 36 & 22 \\
$50 \%$ compliance in single-trait & & 25 \\
$\quad$ field; 5\% refuge in 2-trait field & 42 & \\
20\% refuge in 2-trait field & & 23 \\
Insecticide use in refuge (Si =0.3) & 37 & 14 \\
$5 \%$ refuge in 2-trait field & 28 & 24 \\
$50 \%$ compliance in single-trait & & \\
field; 5\% refuge in 2-trait field & 40 & \\
20\% refuge in 2-trait field & & \\
\hline
\end{tabular}

sistance to Cry3Bbl evolved very fast (2-4 yr) in times similar to those shown in Table 10, whereas resistance to Cry34/35Ab1 evolved in 37-44 yr. In all of these scenarios, the pyramid had greater durability than sequential use of the two toxins.

\section{Discussion}

The following conclusions can be drawn from a summary of the standard, hypothetical simulations. As expected, refuge level ( 5 to $20 \%$ ) had very little influence on the results unless the refuges were treated with insecticides. This supports previous work by Onstad et al. (2001), Storer (2003) and Onstad (2006). Results demonstrate that evolution of resistance is generally delayed by pyramids compared with deployment of a single-toxin corn hybrid. However, soil insecticide use in the refuge reduces this delay and quickens the evolution of resistance.

In this study, resistance evolved faster as fecundity increased for survivors of insecticidal corn. This result supports the conclusions of Heimpel et al. (2005) who used an abstract, but similar single-locus, model to demonstrate that high density-independent egg mortality or low fecundity delays evolution of resistance. Thus, effects on fecundity must be measured to predict which resistance management plans will work well.

The significant differences found in the results calculated with the multiplicative algorithm for survival (Table 2) and the minimum single survival rate suggest that pyramids must be empirically evaluated for efficacy before developing IRM plans. It is possible that epistasis in the plant involving interference between gene expression may reduce effectiveness of one or both toxins in the plant. Or, alternatively, the interaction of toxins in the pest may reduce effectiveness.

Some of our hypothetical results support the work of Roush (1998) and Gould et al. (2006). All three studies concluded that high initial allele frequencies could lead to rapid evolution of resistance. The gen- 
eral results of Roush (1998) and Gould et al. (2006) are also in agreement with our conclusion from this study that pyramided traits are more durable in landscapes without single-trait corn. Toxin traits lose efficacy more quickly when single-trait and pyramided corn hybrids are planted within rootworm-dispersal distance of each other. Our conclusion that pyramids are superior to sequential deployment of toxins when initial allele frequencies are small (0.0001) supports Roush's results based on initial resistance-allele frequencies of 0.001 . We concluded that when initial allele frequencies are close to 0.1 (instead of the standard 0.0001) for both resistance loci, pyramids are generally ineffective and sequential deployment of toxins is better.

In the case study involving transgenic corn expressing Cry34/35Ab1 and Cry3Bb1, the pyramid delayed evolution of resistance longer than a single trait corn hybrid and longer than a sequence of toxins based on at least one resistance-allele frequency remaining below $50 \%$.

It is interesting that in both the hypothetical study and the case study, intermediate levels of dispersal by males delayed resistance evolution the longest. Caprio (2001) analyzed two models and also determined that intermediate levels of dispersal delayed resistance more than other levels. However, it is equally interesting that the superiority of complete mixing or no dispersal by males depended on the effect of the resistance gene. With a minor gene providing at most $44 \%$ survival for homozygotes (case study), no dispersal from the natal patch delayed evolution of resistance much more than complete mixing of the males. In the hypothetical study of major genes conferring $100 \%$ survival for homozygotes, the opposite was true. This phenomenon should be explored more fully in the future. In general, our results support the conclusions of Caprio (2001), who found that nonrandom mating increased the rate at which insects adapted to transgenic crops, but determined that IRM programs using refuges should not over-emphasize random mating.

The recent registration of the pyramided SmartStax and associated reduction of required refuge from 20 to $5 \%$ for this product in the Corn Belt (USEPA 2009) sets the stage for a spatial mosaic of toxin combinations and refuge requirements to co-occur in an area. The reduction in refuge for a pyramided product is well supported by past modeling efforts (i.e., evolution of resistance is not very sensitive to refuge levels in the 5-20\% range; Onstad et al. 2001, Storer 2003); however, a marketplace of various transgenic products with different refuge requirements will require additional emphasis on grower education and IRM compliance. The modeling results from this study demonstrate the importance of farmers following IRM compliance requirements when planting rootworm-protected transgenic hybrids; especially when insecticide is used in the refuge (Table 11). Landscape considerations (e.g., regional coordination of planting) will be more im- portant as additional pyramided crops are commercialized (Onstad 2008).

This modeling study brings to the forefront an issue that to date has only received minimal attention when regulatory decisions pertaining to rootworm-protected plants have been made. The evolution of major resistance genes must be delayed, but how should minor resistance genes be managed and regulated? The case study involved at least one minor gene: the maximum survival conferred by the observed gene for resistance to Cry34/35Ab1 was estimated to be $9 \%$. It has also been called incomplete resistance (Tabashnik et al. 2005). At 50\% resistance allele frequency, a population with a minor gene conferring $9 \%$ maximum survival would have a mean population survival of $<3 \%$ on toxic plants. Future regulatory consideration should be given to the potential interaction among major and minor resistance genes in plants and the role of major and minor resistance genes in IRM (Gassmann et al. 2009).

The conclusions drawn from the modeling results depend on several major assumptions. An underlying assumption of this study was that no cross-resistance existed between the two hypothetical or the two real resistance genes (case study). It is generally believed that cross-resistance will lead to faster evolution of resistance and shorter time to control failures in the field (Caprio 1998). In the case study, rarer resistance genes conferring much greater survival to each toxin were not included along with the two "real" genes. Because these rare genes may occur at some time, future modeling work should evaluate a combination of genes with smaller and larger effects on survival to each toxin. Additional work should focus on the variety of landscapes that may exist with multiple and single-toxin cornfields with dynamic transitions in the prevalence of single-trait fields to pyramided cornfields.

\section{Acknowledgments}

We thank Jungkoo Kang and two anonymous referees for reading the first draft of the manuscript. This project was supported by a gift to the University of Illinois from Syngenta. This article is contribution 1302 of the Department of Entomology, Institute of Agriculture and Natural Resources, University of Nebraska-Lincoln.

\section{References Cited}

Boetel, M. A., and B. W. Fuller. 1997. Seasonal emergencetime effects on adult longevity, fecundity, and egg viability of northern and western corn rootworm (Coleoptera: Chrysomelidae). Environ. Entomol. 26: 12081212.

Branson, T. F., P. L. Guss, and J. J. Jackson. 1977. Mating frequency of the western corn rootworm. Ann. Entomol. Soc. Am. 70: 506-508.

Caprio, M. A. 1998. Evaluating resistance management strategies for multiple toxins in the presence of external refuges. J. Econ. Entomol. 91: 1021-1031. 
Caprio, M. A. 2001. Source-sink dynamics between transgenic and non-transgenic habitats and their role in the evolution of resistance. J. Econ. Entomol. 94: 698-705.

Coats, S. A., J. A. Mutchmor, and J. J. Tollefson. 1987. Regulation of migratory flight by juvenile hormone mimic and inhibitor in the western corn rootworm (Coleoptera: Chrysomelidae). Ann. Entomol. Soc. Am. 80: 697-708.

Crowder, D. W., and D. W. Onstad. 2005. Using a generational time-step model to simulate the dynamics of adaptation to transgenic corn and crop rotation by western corn rootworm (Coleoptera: Chrysomelidae). J. Econ. Entomol. 98: 518-533.

Gassmann, A. J., D. W. Onstad, and B. R. Pittendrigh. 2009. Evolutionary analysis of herbivorous insects in natural and agricultural environments. Pest Manag. Sci. 65: 11741181.

Godfrey, L. D., L. J. Meinke, R. J. Wright, and G. L. Hein. 1995. Environmental and edaphic effects on western corn rootworm (Coleoptera: Chrysomelidae) overwintering egg survival. J. Econ. Entomol. 88: 1445-1454.

Godfrey, L. D., and F. T. Turpin. 1983. Comparison of western corn rootworm (Coleoptera: Chrysomelidae) adult populations and economic thresholds in first-year and continuous corn fields. J. Econ. Entomol. 76: 10281032.

Gould, F., M. B. Cohen, J. S. Bentur, G. C. Kennedy, and J. van Duyn. 2006. Impact of small fitness costs on pest adaptation to crop varieties with multiple toxins: a heuristic model. J. Econ. Entomol. 99: 2091-2099.

Gray, M. E., T. W. Sappington, N. J. Miller, J. Moeser, and M. O. Bohn. 2009. Adaption and invasiveness of western corn rootworm: intensifying research on a worsening pest. Annu. Rev. Entomol. 54: 303-321.

Gray, M. E., and K. L. Steffey. 1998. Corn rootworm (Coleoptera, Chrysomelidae) larval injury and root compensation of 12 maize hybrids, an assessment of the economic injury index. J. Econ Entomol. 91: 723-740.

Hammack, L. 1995. Calling behavior in female western corn rootworm beetles (Coleoptera: Chrysomelidae). Ann. Entomol. Soc. Am. 88: 562-569.

Heimpel, G. E., C. Neuhauser, and D. A. Andow. 2005. Natural enemies and the evolution of resistance to transgenic crops by pest insects: the role of egg mortality. Environ. Entomol. 34: 512-526.

Hibbard, B. E., M. L. Higdon, D. P. Duran, Y. M. Schweikert, and M. R. Ellersieck. 2004. Role of egg density on establishment and plant-to-plant movement by western corn rootworm larvae (Coleoptera: Chrysomelidae). J. Econ. Entomol. 97: 871-882.

Hill, R. E. 1975. Mating, oviposition patterns, fecundity and longevity of the western corn rootworm. J. Econ. Entomol. 68: 311-315.

Hurley, T. M., and P. D. Mitchell. 2008. Insect resistance management: adoption and compliance. Chapter 11. In D. W. Onstad [ed.], Insect resistance management: biology, economics and prediction. Academic, Burlington, MA.

Lefko, S. A., T. M. Nowatzki, S. D. Thompson, R. R. Binning, M. A. Pascual, M. L. Peters, E. J. Simbro, and B. H. Stanley. 2008. Characterizing laboratory colonies of western corn rootworm (Coleoptera: Chrysomelidae) selected for survival on maize containing event DAS59122-7. J. Appl. Entomol. 132: 189-204.

Levine, E., J. L. Spencer, S. A. Isard, D. W. Onstad, and M. E. Gray. 2002. Adaptation of the western corn rootworm to crop rotation: evolution of a new strain in response to a management practice. Am. Entomol. 48: 94-107.

Meihls, L. N., M. L. Higdon, B. D. Siegfried, N. J. Miller, T. W. Sappington, M. R. Ellersieck, T. A. Spencer, and B. E. Hibbard. 2008. Increased survival of western corn rootworm on transgenic corn within three generations of on-plant greenhouse selection. Proc. Nat. Acad. Sci. U.S.A. 105: 19177-19182.

Meinke, L. J., T. W. Sappington, D. W. Onstad, T. Guillemaud, N. J. Miller, J. Komaromi, N. Levay, L. Furlan, J. Kiss, and F. Toth. 2009. Western corn rootworm (Diabrotica virgifera virgifera LeConte) population dynamics. Agric. For. Entomol. 11: 29-46.

Meinke, L. J., B. D. Siegfried, R. J. Wright, and L. D. Chandler. 1998. Adult susceptibility of Nebraska western corn rootworm (Coleoptera: Chrysomelidae) populations to selected insecticides. J. Econ. Entomol. 91: 594600.

Metcalf, R. L. 1986. Methods for the study of pest $D i$ abrotica, pp. vii-xv. In J. L. Krysan and T. A. Miller [eds.], Springer, New York.

Microsoft. 2002. Excel 2002. Microsoft, Seattle, WA.

Miller, N. J., T. Guillemaud, R. Giordano, B. D. Siegfried, M. E. Gray, L. J. Meinke, and T. W. Sappington. 2009. Genes, gene flow and adaptation of Diabrotica virgifera virgifera. Agric For. Entomol. 11: 47-60.

Moellenbeck, D. J., M. L. Peters, J. W. Bing, J. R. Rouse, L. S. Higgins, L. Sims, T. Nevshemal, L. Marshall, R. T. Ellis, P. G. Bystrak, et al. 2001. Insecticidal proteins from $\mathrm{Ba}$ cillus thuringiensis protect corn from corn rootworms. Nat. Biotechnol. 19: 668-672.

Onstad, D. W. 2006. Modeling larval survival and movement to evaluate seed mixtures of transgenic corn for control of western corn rootworm (Coleoptera: Chrysomelidae) J. Econ. Entomol. 99: 1407-1414.

Onstad, D. W. 2008. Major issues in insect resistance management. Chapter 1. In D. W. Onstad [ed.], Insect resistance management: biology, economics and prediction. Academic, Burlington, MA.

Onstad, D. W., and L. L. Buschman. 2006. Evaluation of oviposition deterrence in the management of resistance to transgenic corn by European corn borer (Lepidoptera: Crambidae). J. Econ. Entomol. 99: 2100-2109.

Onstad, D. W., C. A. Guse, J. L. Spencer, E. Levine, and M. E. Gray. 2001. Modeling the dynamics of adaptation to transgenic corn by western corn rootworm (Coleoptera: Chrysomelidae). J. Econ. Entomol. 94: 529-540.

Onstad, D. W., B. E. Hibbard, T. L. Clark, D. W. Crowder, and K. G. Carter. 2006. Analysis of density-dependent survival of Diabrotica (Coleoptera: Chrysomelidae) in cornfields. Environ. Entomol. 35: 1272-1278.

Quiring, D. T., and P. R. Timmins. 1990. Influence of reproductive ecology on feasibility of mass trapping $\mathrm{Di}$ abrotica virgifera virgifera (Coleoptera: Chrysomelidae). J. Appl. Ecol. 27: 965-982.

Roush, R. T. 1998. Two-toxin strategies for management of insecticidal transgenic crops: can pyramiding succeed where pesticide mixtures have not? Phil. Trans. R. Soc. Lond. B 353: 1777-1786.

Sappington, T. W., B. D. Siegfriend, and T. Guillemaud. 2006. Coordinated Diabrotica genetics research: accelerating progress on a urgent pest problem. Am. Entomol. 52: $90-97$.

Spencer, J. L., and E. Levine. 2008. Resistance to crop rotation. Chapter 8. In D. W. Onstad [ed.], Insect resistance management: biology, economics and prediction. Academic, Burlington, MA. 
Storer, N. P. 2003. A spatially-explicit model simulating western corn rootworm (Coleoptera: Chrysomelidae) adaptation to insect resistant maize. J. Econ. Entomol. 96: $1530-1547$.

Storer, N. P., J. M. Babcock, and J. M. Edwards. 2006. Field measures of western corn rootworm (Coleoptera: Chrysomelidae) mortality caused by Cry $34 / 35 \mathrm{Abl}$ proteins expressed in maize event 59122 and implications for trait durability. J. Econ. Entomol. 99: 1381-1387.

Tabashnik, B. E., T. J. Dennehy, and Y. Carriere. 2005. Delayed resistance to transgenic cotton in pink bollworm. Proc. Natl. Acad. Sci. U.S.A. 102: 15389-15393.

[USEPA] United States Environmental Protection Agency. 2009. Pesticide fact sheet. (www.epa.gov/oppbppd1/ biopesticides/pips/smartstax-factsheet.pdf).

Urias-Lopez, M. A., and L. J. Meinke. 2001. Influence of western corn rootworm (Coleoptera: Chrysomelidae) larval injury on yield of different types of maize. J. Econ. Entomol. 94: 106-111.

Vaughn, T. T., T. Cavato, G. Brar, T. Coombe, T. DeGooyer, S. Ford, M. Groth, A. Howe, S. Johnson, and K. Kolacz. 2005. A method of controlling corn rootworm feeding using a Bacillus thuringiensis protein expressed in transgenic maize. Crop Sci. 45: 931938.

Walters, F. S., C. M. Stacy, M. K. Lee, N. Palekar, and J. S. Chen. 2008. An engineered chymotrypsin/cathepsin $\mathrm{G}$ site in domain I renders Bacillus thuringiensis Cry3A active against western corn rootworm larvae. Appl. Environ. Microbiol. 74: 367-374.

Received 17 June 2009; accepted 29 December 2009. 